\title{
Toward a Theory of Charitable Fund-Raising
}

James Andreoni

University of Wisconsin-Madison

Private providers of public goods, such as charities, invariably enlist fund-raisers to organize and collect contributions. Common in charitable fund-raising is seed money, either from a government grant or from a group of "leadership givers," that launches the fund drive and generates additional gifts. This paper provides a theoretical basis for fund-raisers and seeds to charity. The primary assumption is that there is a range of increasing returns at low levels of provision of the public good. It is shown that fund-raisers have a natural and important role, and that sometimes only a small amount of seed money can grow into a substantial charity.

\section{Introduction}

Economic research on altruism, public goods, and charitable giving has flourished over the past decade. The analysis to date has focused almost exclusively on donors - the supply side of charity-and has left unexplored the role played by fund-raisers - the demand side. Yet fund-raising is a vibrant, innovative, and highly professional industry. According to one estimate, about 115,000 organizations hire fundraising staff and consultants, spending $\$ 2$ billion per year on fundraising. In 1995 the 25 largest charities spent an average of over $\$ 25$ million each on fund-raising, or about 14 percent of charitable gifts. ${ }^{1}$

I am grateful to the National Science Foundation and the University of Wisconsin Vilas Associates Fund for financial support; to Marc Bilodeau, Peter Cramton, Preston McAfee, Larry Samuelson, Al Slivinski, Rich Steinberg, Lise Vesterlund, the editor, and an anonymous referee for helpful comments; and to Deena Ackerman for valuable research assistance.

${ }^{1}$ The figures on the overall industry are taken from Kelly (1997). The 25 largest charities are those identified by Money Magazine Online: http:/ / money/features/ charity_1196/top25.html. 
Understanding fund-raising may be important for improving policy predictions. In the 1980 s several policy changes resulted in reduced government grants to charities and a reduced tax preference for donations. While economists predicted dire consequences for charities, contributions continued to rise in the 1980s. Several authors have conjectured that, had the models accounted for the vigorous response by fund-raisers, the predictions might have been better. ${ }^{2}$

This paper begins the task of including fund-raisers by modeling them alongside donors as active participants in the market for privately provided public goods. In doing so, I distinguish between two different types of fund drives, each with different incentives, constraints, and strategies. The first type is capital campaigns. They characterize new charities, or major new initiatives of existing charities, and, as the name implies, involve projects with large fixed costs of capitalization. Examples include buying expensive equipment or constructing new buildings. The second type is continuing campaigns. They raise the operating funds for items such as salaries, supplies, and maintenance for charities that are already capitalized.

This paper, the first in a research program, will focus exclusively on capital campaigns. I begin here because capital campaigns are generally the origins of charitable organizations. In addition, they are characterized by several features that appear to conflict with the intuition of free riding. Foremost among them is that capital campaigns rely heavily on "seed grants" and large "leadership gifts" that are publicly announced before the general fund drive begins. In fact, a well-known rule of thumb for capital campaigns is that onethird of the goal must be raised in a "quiet phase" before the public fund drive is launched. One might guess that such leadership gifts would only encourage free riding among later givers, whereas fundraisers surely believe that they encourage gifts. By contrast, continuing campaigns turn directly to general fund-raising, without relying on the leadership phase.

While the discussion will be carried out in terms of capital campaigns, the application of the model is much broader. The key to the model is the assumption that there are initially some economies of scale in producing the public good. This is obviously true of capital investments, such as buildings, which must meet some critical threshold before they become productive. However, any public good

\footnotetext{
${ }^{2}$ See Clotfelter (1990) and Auten, Cilke, and Randolph (1992) for discussions of the effects of the tax reforms of the 1980s on charitable giving. Economists did accurately predict the effect of tax changes on the timing of gifts, however, as seen in Randolph (1995).
} 
that has increasing returns at low levels of provision will fit into the model presented here and can form the basis for fund-raising and leadership giving.

Note that one obvious way to explain leadership gifts is to consider social pressures and warm glows to giving. While they are clearly important, this paper will begin with the focus on purely economic variables. This is done for simplicity and to motivate more general results. Adding social effects, as is shown later in the paper, only strengthens the findings.

In Section II, I discuss some central features of capital campaigns that the model must explain. Section III provides important theoretical background, and Section IV presents the basic model. Sections $\mathrm{V}$ and VI look at the role of seed grants and leadership gifts. Section VII expands the model to include social effects, and Section VIII considers the possibility of seed subsidies.

\section{Capital Campaigns}

In the spring of 1995, Wisconsin Governor Tommy Thompson offered $\$ 27$ million in state bonds to finance a new $\$ 72$ million basketball arena for the University of Wisconsin, on the condition that the rest of the money be raised by private donations. A few days later, on April 1, 1995, Wisconsin's U.S. Senator Herb Kohl, who is also a wealthy entrepreneur, pledged $\$ 25$ million to the project, which would now be called the Kohl Center. On June 27, 1995, Ab Nichols, a former University of Wisconsin basketball star, pledged \$10 million. In November of 1995 the Kellner family pledged \$2.5 million. By the time the university formally announced its public fund-raising campaign in February of 1996, it needed only $\$ 7$ million to reach its goal. Building for the arena began in May of 1996, a little more than a year after the governor's offer. ${ }^{3}$

The Lawrenceville School, a private high school in New Jersey, just completed a 5-year, $\$ 125$ million capital campaign. The drive was described in the October 1992 issue of Fund Raising Management magazine as "a technical and diplomatic juggling act requiring a timetable divided into three phases: Preparation, Nucleus Fund and the Public Campaign"' (p. 21). During the preparation phase, the fund-raisers gathered information about potential donors, especially those who would be capable of contributing $\$ 25,000$ or more. In the

\footnotetext{
${ }^{3}$ This information was drawn from various issues of Wisconsin newspapers: the Wisconsin State Journal (June 27, 1995, p. 1A; September 12, 1995, p. 1B; October 28, 1995, p. 2D), the Capital Times (January 17, 1996, p. 1B), and the Milwaukee Sentinel (November 13, 1995, sports page 4).
} 
nucleus fund stage, the school set out to raise one-third of the goal from these large donors. After quietly securing $\$ 42$ million in the nucleus fund stage, the fund-raisers were ready for the public campaign phase. With a lavish kickoff banquet and public relations blitz, the school announced its campaign. It then relied on small contributions raised from mailings, phone solicitations, and class reunions to complete the drive (see Fund Raising Management, October 1992, pp. 19-25; August 1996, pp. 21-24).

These two examples are typical of many capital campaigns. Skimming recent issues of Fund Raising Management yields many similar cases in which large donations from governments or from a small group of "leadership givers" act as a seed to grow a successful major capital fund drive. The phenomenon is so prevalent that experts in fund-raising have developed rules of thumb to describe it. For instance, Robert F. Hartsook in Fund Raising Management (August 1994, p. 32) advised that "the leadership commitment . . . should represent no less than 20 percent of the capital campaign goal." Jerold Panas, a professional fund-raiser and author of "how-to" books for fund-raisers, suggests that "if . . . there is not the potential for receiving 40 percent of your objective from your top twenty gifts, your campaign is likely to be moribund" (Fund Raising Management, August 1994, p. 27). The Lawrenceville School was following a similar and often-quoted rule: raise one-third of the goal in a "quiet phase" before announcing the general public fund drive.

In the economic models, charities are generally treated as inert organizations without goals, strategies, or influence. ${ }^{4}$ However, the fund-raising apparatus appears to play a very important role in providing public goods. ${ }^{5}$ Complicating the role of fund-raisers in capital campaigns is the fact that the charitable goods require significant fixed costs. For instance, a basketball arena or a school building needs to be of a certain minimum size and quality before it can be useful. Similarly, a public television or radio station needs expensive equipment before a minute of broadcasting can be produced. Unless there is a single large benefactor who is willing to guarantee this minimum quality, an equilibrium will spring up at zero contributions, even though another equilibrium exists at an interior point.

\footnotetext{
${ }^{4}$ Several authors have looked at nonprofit entrepreneurship. Recent contributions include Bilodeau and Slivinski (1996a). Earlier theoretical models of fundraising have focused on maintaining the proper incentives of the fund-raisers and managers from the point of view of donors (see Rose-Ackerman 1982, 1987).

${ }^{5}$ Studies of charitable organizations have found fund-raising to be positively related to donations. The most recent study, by Khanna, Posnett, and Sandler (1995), shows that government grants and large "legacies" also appear to increase the donations of others. The type of effect will be illustrated in Sec. V.
} 
Until the charity is sure to reach the threshold, no one has an incentive to give, meaning, of course, that without certain efforts the threshold may never be exceeded.

This paper will discuss the origins of privately provided public goods and, in particular, the role of seed money. In one version of the model, a government grant provides seed money. In a second version, fund-raisers solicit the seed money from donors. To make the model interesting, I consider two additional assumptions. First, the public good must meet a minimum quality threshold before it yields any services. Second, fund-raising is costly. The result is that the seed money is often necessary, but need be only a small fraction of the ultimate equilibrium level of contributions, and in fact need be only a small fraction of the minimum threshold, in order to push the economy off the zero provision level of the public good. Just as in the Kohl Center or the Lawrenceville School, help from the government or from large private donors-each well below the amount required to build the good-can seed the millions of dollars of small private contributions needed to complete the project.

It is important to note that this is not a paper about mechanism design. Rather, this is a positive look at the role of seeds and fundraisers in starting charitable organizations. Why don't charities simply adopt one of the many mechanisms suggested in the economics literature? Aside from the fact that these mechanisms can be complicated and abstract, charities rely on many donors, perhaps thousands, and the organizational activity of the charity is costly. Organizing such a mechanism with so many people involved could be prohibitively expensive. The objective here is to understand why charities invest in organizing only a relatively small band of major contributors and then count on them to jump-start a general fund drive.

\section{Theoretical Foundation}

This section reviews the model of privately provided public goods that forms the basis for the later analysis. This model was introduced by Warr $(1982,1983)$ and developed further by others. ${ }^{6}$ Individuals are each endowed with money $m_{i}$, which they can allocate between consumption of a private good, $x_{i}$, and gifts to the public good, $g_{i}$. Assume that units are normalized so that $x$ and $g$ can be expressed in dollars; hence each person faces a budget $x_{i}+g_{i}=m_{i}$. Let $G=$ $\sum_{i=1}^{n} g_{i}$ be the total contributions to the public good. Individuals are

\footnotetext{
${ }^{6}$ Examples include Roberts (1984, 1987), Bergstrom, Blume, and Varian (1986), and Andreoni (1988). See Sandler (1992) for a detailed discussion of this literature.
} 
taken to have preferences $u_{i}=u_{i}\left(x_{i}, G\right)$, which are continuous and strictly quasi-concave. Note that so far I have not assumed that there is a minimum threshold for the production of the public good; hence there is no range of increasing returns. As we shall see, the assumption of a threshold will create an important nonconvexity. For that reason, I shall refer to this standard model as the convex case throughout the paper. It will serve as an important reference point.

The provision of the public good is modeled as a simultaneous play Nash equilibrium game. Define $G_{-i}=\sum_{j \neq i} g_{j}$ as the contributions of everyone except person $i$. Alternatively, we can write $G=$ $G_{-i}+g_{i}$. Under Nash equilibrium, each person's strategy is a contribution $g_{i}, 0 \leq g_{i} \leq m_{i}$, with $G_{-i}$ taken as given. With this framework, an individual's maximization problem can be written as

$$
\begin{gathered}
\max _{x_{i}, g_{i}} u_{i}\left(x_{i}, g_{i}+G_{-i}\right) \\
\text { subject to } x_{i}+g_{i}=m_{i}, \\
g_{i} \geq 0 .
\end{gathered}
$$

Since gifts of others are treated as exogenous in the individual's maximization problem, it is equivalent to add the constant $G_{-i}$ to both sides of the constraints and then to think of individuals as choosing $G$ rather than $g_{i}$. Hence, the maximization above is equivalent to

$$
\begin{gathered}
\max _{x_{i}, G} u_{i}\left(x_{i}, G\right) \\
\text { subject to } x_{i}+G=m_{i}+G_{-i}, \\
G \geq G_{-i} .
\end{gathered}
$$

Ignoring the inequality constraint, one can easily see that each individual will have a solution to this problem of the form $G=$ $f_{i}\left(m_{i}+G_{-i}\right)$ or, equivalently, $g_{i}=f_{i}\left(m_{i}+G_{-i}\right)-G_{-i}$. However, keeping the inequality constraint in mind, we can write the individual supply function as

$$
g_{i}=\max \left\{f_{i}\left(m_{i}+G_{-i}\right)-G_{-i}, 0\right\} .
$$

We can add the further assumption that both the public good and the private good are normal; hence $0<f_{i}^{\prime}<1$.

Given these supply functions, we can define a Nash equilibrium as a vector of gifts $\left(g_{1}^{*}, g_{2}^{*}, \ldots, g_{n}^{*}\right)$ such that the supply functions in (1) map this vector into itself. Under the assumptions made, it can be shown that a Nash equilibrium will exist and that it will be unique. Both of these propositions have been shown by Bergstrom 
et al. (1986) and follow directly from the assumption of normal goods. For brevity, interested readers are referred to the original source.

Before continuing with the new model, I need to add two more assumptions. First, assume that if we were to remove any threshold, the equilibrium $G^{*}=\sum_{i=1}^{n} g_{i}^{*}$ would always be positive. Furthermore, let $C^{*}$ be the equilibrium set of contributors to the public good in the convex case. Then assume that the number of people in this set is at least two.

\section{A Model}

In this section and in the remainder of the paper, I shall often refer to the model above as an important reference point. Hence, any mention of $G^{*}$ or $g_{i}^{*}$ will be referring to the Nash equilibrium in the convex case.

For the new model, keep all the same assumptions used above, but now define the technology for producing the public good $G$ as including an important nonconvexity:

$$
G= \begin{cases}\sum_{i=1}^{n} g_{i} & \text { if } \sum_{i=1}^{n} g_{i} \geq \bar{G} \\ 0 & \text { if } \sum_{i=1}^{n} g_{i}<\bar{G}\end{cases}
$$

There is now a minimum threshold $\bar{G}$ that contributions must meet or surpass before any benefits of the public good can be consumed. ${ }^{7}$ Note that this implies that there are some fixed costs involved in producing the good or, alternatively, there are increasing returns around the point at which contributions approach $\bar{G}{ }^{8}$

The interesting feature of having fixed costs is that the economy could get "stuck" at an equilibrium of zero contributions. First notice that when $\bar{G}=0$, we are back in the convex case; hence $g_{i}=$ $g_{i}^{*}$ for all $i$ is the unique equilibrium. As $\bar{G}$ increases from zero, the threshold may have absolutely no impact on $g_{i}$. In fact, it is easy to

\footnotetext{
${ }^{7}$ Note that a more general model would assume that $G=\alpha \sum_{i=1}^{n} g_{i}$ if $\sum_{i=1}^{n} g_{i}<$ $\bar{G}$, where $0<\alpha<1$. For instance, if the project fails to reach the threshold, then an inferior alternative public good will be built. Similar results would follow as long as $\alpha$ is small enough to create an additional equilibrium at $G=0$.

${ }^{8}$ Clearly, there are many other less dramatic ways in which increasing returns could have been introduced. However, it is easy to show that equilibria would never occur on an area of increasing returns; hence the assumption of this technology is a simplifying, if extreme, form of increasing returns.
} 


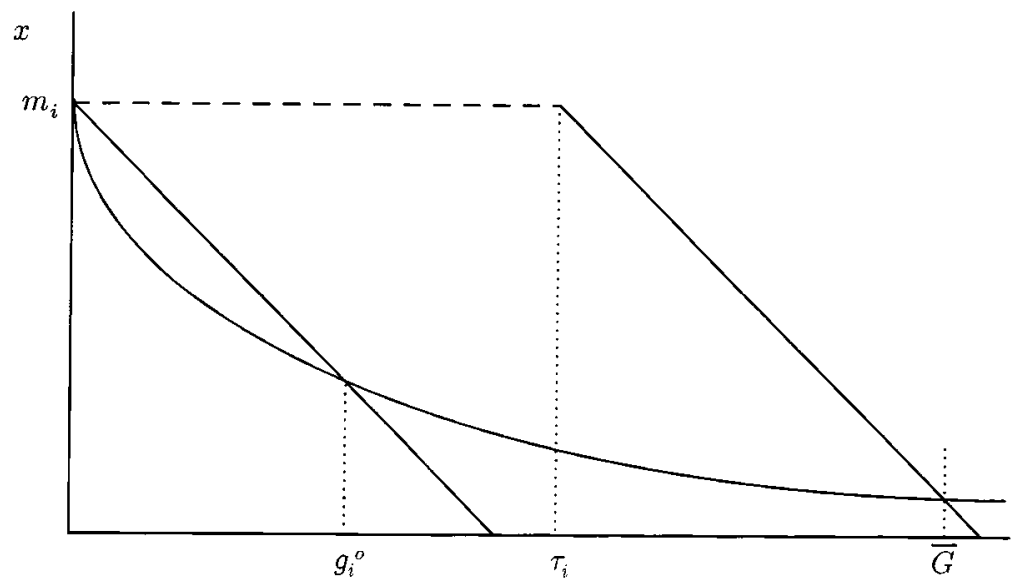

FIG. 1.-Defining $g_{i}^{o}$ and $\tau_{i}$

see that if $\bar{G}$ is below the $g_{i}^{*}$ of any individual, then $\bar{G}$ will have no effect on the existence or uniqueness of any equilibrium.

How big does $\bar{G}$ need to be? Define $g_{i}^{o}$ as the solution to the following for all $i: u_{i}\left(m_{i}-g_{i}^{o}, g_{i}^{o}\right) \equiv u_{i}\left(m_{i}, 0\right)$. Then $g_{i}^{o}$ is the threshold such that if $\bar{G}=g_{i}^{0}$, person $i$ would be just willing to provide all the public good alone, if need be; whereas if the threshold is above $g_{i}^{0}$, this person would not. The solution for $g_{i}^{0}$ can be shown graphically in figure 1 . Clearly, an equilibrium will spring up at $G=0$ if no one is willing to make a solo gift. Hence, define $g_{\max }^{o}=\max \left\{g_{1}^{o}\right.$, $\left.g_{2}^{0}, \ldots, g_{n}^{o}\right\}$ as the highest of these values across all individuals. Then we can make the following proposition.

Proposition 1. The allocation $G=0$ is a Nash equilibrium iff $g_{\max }^{o} \leq \bar{G}$.

Proof. If $g_{i}^{o} \leq \bar{G}$, then the best response to $G_{-i}=0$ will be $g_{i}=0$ for all $i$. Hence, $g_{i}=0$ for all $i$ is a Nash equilibrium. Likewise, suppose that $G=0$ is a Nash equilibrium but $g_{\max }^{o}>\bar{G}$. Then for at least one person $k$ there exists a $g_{k}>\bar{G}$ that yields higher utility than $g_{k}=0$, which contradicts the assumption that $G=0$ is a Nash equilibrium. Q.E.D.

If $\bar{G}$ is too large, then there may be only one equilibrium at $G=$ 0 . The interesting case is one in which $\bar{G}$ is large enough to possibly prevent a charity from springing up, but not so large as to keep it from ever being provided. It turns out that if $\bar{G}<G^{*}$, then we are guaranteed to have two and only two Nash equilibria. This is stated formally in the following proposition.

Proposition 2. If $g_{\text {max }}^{o} \leq \bar{G} \leq G^{*}$, then there will be exactly two Nash equilibria: one at $G=0$ and another at $G=G^{*}$. 
Proof. If follows obviously from proposition 1 that both $G=0$ and $G=G^{*}$ are Nash equilibria. What we need to establish is that there are no other Nash equilibria. Since any $G>\bar{G}$ would have been available in the convex case (where $\bar{G}=0$ ), we have to rule out possibilities for $\bar{G}$ as an equilibrium only when $\bar{G}<G^{*}$.

Consider a $\bar{G}<G^{*}$ and a vector $\left(\bar{g}_{1}, \bar{g}_{2}, \ldots, \bar{g}_{n}\right)$ such that $\bar{g}_{i} \geq$ 0 for all $i$ and $\sum_{i=1}^{n} \bar{g}_{i}=\bar{G}$. Suppose that this allocation is an equilibrium. Let $\hat{g}_{i}=f_{i}\left(m_{i}+\bar{G}_{-i}\right)-\bar{G}_{-i}$. If $\bar{g}_{i}$ is an equilibrium, then it must be that the best response to $\bar{G}_{-i}$ is not a number greater than $\bar{g}_{i}$; that is, $\hat{g}_{i} \leq \bar{g}_{i}$ for all $i$. Since $f_{i}\left(m_{i}+\bar{G}_{-i}\right) \leq \bar{G}<G^{*}=f_{i}\left(m_{i}+\right.$ $\left.G_{-i}^{*}\right)$ for all $i \in C^{*}$ and since $f$ is monotonically increasing, we know that $\bar{G}_{-i}<G_{-i}^{*}$ for all $i \in C^{*}$. Finally, by the assumption that all goods are normal, $-1<f^{\prime}-1<0$. It follows that $\hat{g}_{i}>g_{i}^{*}$ for all $i \in C^{*}$. Since $\bar{g}_{i} \geq \hat{g}_{i}$, it follows that $\bar{g}_{i}>g_{i}^{*}$ for $i \in C^{*}$. But this would imply that $\bar{G}>G^{*}$, a contradiction. Q.E.D.

The next two results follow easily from the discussion above.

Corollary 1 . If $\bar{G}=G^{*}$, then $\left(g_{1}^{*}, g_{2}^{*}, \ldots, g_{n}^{*}\right)$ is the unique interior equilibrium.

Proof. Consider any allocation $\left(\bar{g}_{1}, \bar{g}_{2}, \ldots, \bar{g}_{n}\right)$ not equal to $\left(g_{1}^{*}\right.$, $\left.g_{2}^{*}, \ldots, g_{n}^{*}\right)$ such that $\sum_{i=1}^{n} \bar{g}_{i}=\sum_{i=1}^{n} g_{i}^{*}$. Suppose that $\left(\bar{g}_{1}, \bar{g}_{2}, \ldots\right.$, $\left.\bar{g}_{n}\right)$ is a Nash equilibrium. Then there must be at least one $j \in C^{*}$ such that $\bar{g}_{j}<g_{j}^{*}$, and hence $\bar{G}_{-j}>G_{-j}^{*}$. By monotonicity, $f_{j}\left(m_{j}+\right.$ $\left.\bar{G}_{-j}\right)>f_{j}\left(m_{j}+G_{-j}^{*}\right)=G^{*}$ for $j$, which contradicts the assumption that $\left(\bar{g}_{1}, \bar{g}_{2}, \ldots, \bar{g}_{n}\right)$ is a Nash equilibrium. Q.E.D.

Corollary 2. If $g_{\max }^{o}>\bar{G}$, then $\left(g_{1}^{*}, g_{2}^{*}, \ldots, g_{n}^{*}\right)$ is the unique Nash equilibrium.

Proof. When $g_{\max }^{o}$ is above the threshold $\bar{G}$, then for some $k$ there is a $g_{k}>0$ that is a best response to $G_{-k}=0$. Hence, $G=0$ is no longer a Nash equilibrium. The proof that $\left(g_{1}^{*}, g_{2}^{*}, \ldots, g_{n}^{*}\right)$ is the unique Nash equilibrium is exactly the same as that in corollary 1 , which showed it to be the unique interior equilibrium.

Proposition 2 shows that if the threshold $\bar{G}$ is big enough, it will create another Nash equilibrium at $G=0$; but as long as the threshold is not above $G^{*}$, it will not create any more Nash equilibria. This is true even if by chance the threshold actually equals $G^{*}$. Of course, it is still possible for two Nash equilibria to exist if $\bar{G}>G^{*}$. It is obvious that a threshold $\bar{G}>G^{*}$ means that $G^{*}$ is unavailable as an equilibrium. It is also clear that no equilibrium $G$ will develop above $\bar{G}$. However, it is possible that $\bar{G}$ itself may become an equilibrium. In particular, as long as there exists a Pareto-improving way to allocate gifts such that $\sum g_{i}=\bar{G}$, there will exist a Nash equilibrium at $\bar{G}$. This is shown next.

Proposition 3. Assume $\bar{G}>G^{*}$. If there exists a $\left(\bar{g}_{1}, \bar{g}_{2}, \ldots, \bar{g}_{n}\right)$ 
such that $g_{i}^{*}<\bar{g}_{i} \leq g_{i}^{o}$ for each $i$ and $\sum_{i=1}^{n} \bar{g}_{i}=\bar{G}$, then $\left(\bar{g}_{1}, \bar{g}_{2}, \ldots\right.$, $\left.\bar{g}_{n}\right)$ is a Nash equilibrium.

Proof. First note that since $\sum_{i=1}^{n} \bar{g}_{i}=\bar{G}$, everyone is pivotal; that is, if anyone provides less than $\bar{g}_{i}$, then no public good will be provided. But since $\bar{g}_{i} \leq g_{i}^{o}$ for all $i$, no one has an incentive to provide less than $\bar{g}_{i}$; that is, $\bar{G}$ is Pareto improving. Furthermore, since $g_{i}^{*}<\bar{g}_{i}$ for all $i, G_{-i}^{*}<\bar{G}_{-i}$ for all $i$. By normal goods, no one can increase utility by providing more than $\bar{g}_{i}$. Hence, $\bar{g}_{i}$ is a best response for all i. Q.E.D.

An interesting contrast between propositions 2 and 3 is that when $\bar{G} \leq G^{*}$, there is only one nonzero equilibrium at $G^{*}$. However, when $\bar{G}>G^{*}$, any set of contributions that are between $g_{i}^{o}$ and $g_{i}^{*}$ for all $i$ and sum to $\bar{G}$ may be a Nash equilibrium. In general, there will be a continuum of such equilibria. This case is very similar to the "provision point" models considered by Bagnoli and Lipman (1989). Typically in these models the public good is provided only at the threshold, not above or below, and any contributions above the threshold are either wasted or refunded in some manner. If an interior equilibrium exists, however, it is always at contributions that sum to exactly $\bar{G}$. In our model, the case in which $\bar{G}>G^{*}$ is much like the Bagnoli and Lipman framework since no one has an incentive to give more than the assigned $\bar{g}_{i}$; hence models of provision points can be applied to the fund-raising problem.

This naturally raises the point of what to assume in the event that contributions fail to meet the threshold, $\sum g_{i}<\bar{G}$. There are several possibilities. Funds could be wasted, refunded, or applied to some other (inferior) project. The provision point models often also allow that contributions below the threshold are refunded to the donor. Applying the funds to an alternative project would require a more general model than that presented here but would have consequences similar to those of a refund as long as utility is continuous in the contributions to the inferior project. As far as equilibria are concerned, they are the same regardless of whether a refund is given, the funds are wasted, or an alternative project is built. Because it is simpler, and perhaps more realistic, assume that if gifts do not meet the threshold, the funds are used for some other project that the contributors do not care about and in this sense are wasted. ${ }^{9}$

The next two sections examine how a small grant by government

\footnotetext{
${ }^{9}$ It is interesting to note, however, that experiments run by Bagnoli and McKee (1991) reveal that a refund greatly increases the chance of providing the good. In practice, therefore, charities may find it in their interest to get pledges that will be refunded if the goal is not met. I return to this point in Sec. VI.
} 
or individuals can result in big growth for charity, that is, can remove $G=0$ as an equilibrium. It is assumed throughout that $\bar{G}$ is large enough that a Nash equilibrium exists at $G=0$.

\section{Government Grants}

Imagine that the government levies lump-sum taxes $t_{i}$ on each individual and contributes a grant $T=\sum_{i=1}^{n} t_{i}$ to the public good. It is well known that if $t_{i} \leq g_{i}^{*}$ for all $i$, then the lump-sum tax will be completely crowded out. That is, total giving $G+T$ will remain unchanged (Warr 1982). Since the individual's voluntary gift, $g_{i}^{*}$, is greater than the involuntary gift, $t_{i}$, the individual can simply reduce the voluntary component of the gift so that the total gift, voluntary plus involuntary, equals the value of the pretax gift $g_{i}^{*}$. By the definition of the equilibrium, this is optimal for everyone, and hence, private contributions are completely crowded out by the public grant. This crowding-out hypothesis will greatly simplify the analysis below.

Note that the crowding-out proposition has been the subject of many papers, which show that it is unrealistic and easily rejected when confronted with data. It is used here for its analytical ease. Later I show that qualitatively similar, although technically more complicated, results follow from more general and realistic models of giving, such as warm glow and prestige giving. Likewise, using income or commodity taxes would be more descriptive than simple lump-sum taxes. Similar results follow from more complex taxes but are much more easily shown using lump-sum taxation. ${ }^{10}$

For each $i$ let $\tau_{i}$ be the amount of exogenous giving at which person $i$ is just willing to bring the public good up to the threshold value by acting alone. That is, $\tau_{i}$ is determined implicitly as the solution to

$$
u_{i}\left(m_{i}+\tau_{i}-\bar{G}, \bar{G}\right) \equiv u_{i}\left(m_{i}, 0\right),
$$

where $g_{i}=\bar{G}-\tau_{i}$ is the individual's gift. An illustration of $\tau_{i}$ is shown in figure 1.

The quantity $\tau_{i}$ will be an important variable in determining the necessary size of seeds to charitable giving. This is illustrated in the next proposition.

Proposition 4. Suppose $\bar{G}<G^{*}$ and $g_{\max }^{o}<\bar{G}$. For any lump-sum tax scheme $\left(t_{1}, t_{2}, \ldots, t_{n}\right)$ such that $t_{i} \leq g_{i}^{*}$ for all $i \in C^{*}, t_{i}=0$ for all $i \notin C^{*}$, and $\sum_{j \neq k} t_{j}>\tau_{k}$ for at least one $k \in C^{*}$, there will exist a unique interior Nash equilibrium $G^{\prime}$, where $g_{i}^{\prime}=g_{i}^{*}-t_{i}$ for all $i$ and $G^{*}=G^{\prime}+T$.

${ }^{10}$ Andreoni $(1988,1993)$ examines the validity of the crowding-out hypothesis, and Andreoni and Bergstrom (1996) discuss distortionary taxes in models of privately provided public goods. 
Proof. As in proposition 1 , for some $k$ there exists a $g_{k}>0$ that is a best reply to $G_{-k}=0$; hence $G=0$ is no longer a Nash equilibrium. It is also clear, by the crowding-out hypothesis, that $g_{i}^{\prime}=g_{i}^{*}-t_{i}$ for all $i$ is also a Nash equilibrium. We need to show that this equilibrium is unique.

As before, we need to verify that the threshold is not an equilibrium. Consider person $k$ for whom $\sum_{j \neq k} t_{j}>\tau_{k}$. For this person, $G_{-k}+\sum_{j \neq k} t_{j}>\tau_{k}$. By the assumption of normal goods and by the definition of $\tau$, person $k$ will have a best response $g_{k}>\bar{G}-\tau_{k}$. Hence, there is not an equilibrium at the threshold.

To complete the proof, we need to show that it is indeed possible to find a tax vector that satisfies the conditions of the proposition, that is, $t_{i} \leq g_{i}^{*}$ for all $i$ and $\sum_{j \neq k} t_{j}>\tau_{k}$ for some $k$. Suppose $\tau_{k}=$ $\min \left\{\tau_{1}, \tau_{2}, \ldots, \tau_{n}\right\}$. It is easy to show (see Andreoni and McGuire $1993)$ that the assumption of normal goods implies that $G_{-k}^{*}>\tau_{k}$. Hence, set $t_{i}=g_{i}^{*} \cdot\left[\left(\tau_{k}+\epsilon\right) / G_{-k}^{*}\right]$ for all $i \neq k$ and for some positive $\epsilon$ arbitrarily close to zero, and let $t_{k}$ be any nonnegative number less than $g_{k}^{*}$. Then $t_{i}<g_{i}^{*}$ for all $i$, and $\sum_{j \neq k} t_{j}>\tau_{k}$. Q.E.D.

This proposition states that if the government raises taxes on people other than $i$ by an amount at least as high as $\tau_{i}$, then there will be a unique Nash equilibrium in which the total provision, private gifts plus taxes, will be identical to the Nash equilibrium in the original convex version of this economy. Notice that, by definition, $\tau_{i}$ will be less than $g_{i}^{o}$ for each $i$; hence, $\tau_{i}$ will be less than $\bar{G}$. The implication of this is that the seed provided by the government can be below the threshold $\bar{G}$. In fact, the seed can be chosen with the most generous person, that is, with the lowest $\tau$, in mind.

Several other interesting things can be noted. First, if $\bar{G}>G^{*}$ but there still exists an interior Nash equilibrium at $\bar{G}$ and if the government contributes a grant $T$ that is large enough to induce one person to give to the public good, then in equilibrium that person need not be the sole contributor to the public good. As in proposition 3, as long as there is a Pareto-improving way to allocate contributions such that the threshold is met, such an allocation can be an equilibrium. In general there may be a continuum of such equilibria. All that the government seed does is to guarantee that $G=0$ is no longer an equilibrium. ${ }^{11}$

A second interesting point is that giving can also be seeded in situations less restrictive than those spelled out in this proposition. In fact, as shown by Bergstrom et al. (1986), taxing nongivers will

\footnotetext{
${ }^{11}$ At this point one could consider other assumptions on fund-raising, such as sequential giving among givers. As Admati and Perry (1991) show, this will also lead to an equilibrium that meets the threshold. This will be discussed more later.
} 
increase the equilibrium level of public goods. The implication for this model is that if nongivers are taxed, then the seed will generate even greater gifts. All that is needed is that the tax on individuals other than $i$ be greater than $\tau_{i}$ for at least one $i$ in order to rule out a Nash equilibrium at the origin. If this is accomplished, the resulting Nash equilibrium will be whatever the unique interior Nash equilibrium would have been for that tax scheme in the ordinary convex case. As we know from Bergstrom et al., if nongivers are taxed or if individuals are taxed in excess of their original gift, then the Nash equilibrium will be higher than if only givers had been taxed and at an amount lower than the original gift. This is shown next.

Corollary 3. Assume $\bar{G}<G^{*}$. Let $G^{* *}$ be the interior Nash equilibrium in the convex case that would result from a lump-sum tax scheme $\left(t_{1}, t_{2}, \ldots, t_{n}\right)$. If $t_{i} \geq 0$ for all $i$ and if $\sum_{j \neq k} t_{j}>\tau_{k}$ for at least one $k$, then $G^{* *}$ will be the unique Nash equilibrium and $G^{* *}+T \geq G^{*}$.

Proof. First find a vector of taxes that satisfies the conditions in proposition 4 . Hence, only givers are taxed. Now adjust that vector of taxes to the desired new vector. Since all changes either will be neutral (by completely crowding out givers) or will be increases in taxes on nongivers and hence cause a nonneutral increase in total giving, $G^{* *}+T \geq G^{*}$. Q.E.D.

This corollary has the natural interpretation that if free riders are taxed, we can get an even bigger bang for each tax dollar collected. What is important, and perhaps surprising, is that $\tau$ need not be large compared with $\bar{G}$. If $\bar{G}$ is close to $g_{i}^{o}$, then the $\tau$ may be quite small. As $\bar{G}$ moves farther above $g_{i}^{o}$, the $\tau$ will grow as well, but the return from government tax dollars in terms of seeding and promoting private gifts may still be substantial. Only when $\bar{G}$ is many times $g_{i}^{o}$ will the seed need to be a significant fraction of the total public good.

These propositions can be illustrated with a simple example. Consider an economy of 100 individuals with identical utility functions $u_{i}=(1-\alpha) \ln x+\alpha \ln (G+\gamma)$. In this example, set $\alpha=0.75, \gamma=$ 200 , and income $m=100$ for all 100 individuals. These parameters imply an interior Nash equilibrium, in the case with no threshold, at $G^{*}=97.09$; hence $g_{i}^{*}=0.9709$ for all $i$, which is about 1 percent of income. The critical value for the threshold is $g_{i}^{o}=46.75$. Suppose for simplicity that the government levies an identical tax on each individual such that $(n-1) t=\tau$, and hence $T=n \tau /(n-1)$. Table 1 shows a number of different outcomes based on different assumptions about the threshold $\bar{G}$.

Look first at case 1 , where $\bar{G}$ is 50 , only 3.25 above $g_{i}^{o}$. Here a total tax of only $T=1.21$ will guarantee that $G^{*}=97.08$ is the unique 
TABLE 1

EXAMPLE

\begin{tabular}{lccccc}
\hline \hline & Case $1:$ & Case 2: & Case 3: & Case 4: & Case 5: \\
& $\bar{G}=50$ & $\bar{G}=75$ & $\bar{G}=100$ & $\bar{G}=150$ & $\bar{G}=200$ \\
\hline$\tau$ & 1.20 & 13.47 & 29.62 & 68.65 & 112.50 \\
$t_{i}=\tau /(n-1)$ & .012 & .136 & .299 & .693 & 1.136 \\
Equilibrium $G+T$ & 97.08 & 97.08 & 100 & 150 & 200 \\
Bang for the buck: $G / T$ & 79.10 & 6.14 & 2.34 & 1.16 & .76 \\
\hline
\end{tabular}

NOTE. $-u_{i}=x_{i}^{.25}(G+200)^{75}$ for all $i, m=100, n=100, G^{*}=97.08$, and $g_{i}^{o}=46.75$. Identical individuals and identical taxation $t_{i}=\tau /(n-1)$ are assumed.

Nash equilibrium. Every dollar of taxes collected generates $\$ 79.10$ of private charity, a substantial bang for the buck. In case 2 , a $\bar{G}$ of 75 is 28.5 above $g_{i}^{o}$, and here taxes $T=13.61$ are enough to guarantee the unique equilibrium at $G^{*}$, with each dollar of taxes generating over $\$ 6.00$ of charity. As the threshold $\bar{G}$ rises above $G^{*}$, as in the last three cases, the threshold itself becomes the equilibrium. But as we can see in case 5 , even when the threshold is more than twice $G^{*}$, each dollar of tax revenue still raises an additional 76 cents of private charity.

I can also illustrate corollary 3. Suppose in the example above that an amount of income equal to $g_{i}^{*}$ is transferred from half the population to the other half; hence the richer half will have income of $\$ 100.97$ and the poorer half $\$ 99.03$. Now, because of the crowdingout hypothesis, only the rich half will give, but the equilibrium $G^{*}$ will stay the same. If we retain the assumption of taxing everyone equally, then in case 1 the $\tau_{i}$ for the givers falls to 0.73 ; hence the $\operatorname{tax} t_{i}$ falls as well and the bang for the buck rises to $\$ 131.35$. Providing any level of $G$ now requires less total taxation. For instance, the bang for the buck in the case $\bar{G}=75$ is 6.46 , for $\bar{G}=100$ is 2.42, and for $\bar{G}=200$ is 0.77 .

\section{Fund-Raising}

Imagine again the convex case. Here there is no role for fundraising. To understand it in this context we might turn to models of advertising and information, or perhaps appeal to ad hoc models of social pressure. With the existence of a nonconvexity, however, fund-raising plays a natural role in coordinating givers to overcome the equilibrium at zero contributions.

Fund-raising is modeled in three stages. The first stage is the selection stage. Here the charity selects a subset of the population to act as leaders. This stage is done "quietly" by the charity. One can think 
of this as the time at which the fund-raiser assesses the feasibility of the project and does "market research" into the potential donors. In the second stage, called the leadership phase, the charity organizes the leaders and allows them to make pledges of contributions. Just as with real fund-raising, these pledges are binding. ${ }^{12}$ The leadership phase is thus a game among the leaders. An interesting aspect of the leadership phase is that being a leader is voluntary; hence the charity cannot make people worse off by being leaders. Models of the sequential provision of public goods can be exploited to analyze this stage of the game. It should also be added that organizing leaders is costly, and the greater the number of leaders the greater the cost of the fund-raising. This gives charities (and leaders) an incentive to keep the group small. The final stage is called the contribution stage. In this stage the charity turns to the general public for massive fund-raising. This stage is modeled as a simultaneous contribution public goods game. The charity announces the leadership pledges and then collects contributions to the public good. The crux of the model is that the charity will choose leaders, and select a game to run among the leaders, so that when they turn to the general contributions stage they have omitted zero as a Nash equilibrium.

\section{A. Fund-Raising in a Pure-Altruism Model}

Define the set of leaders, $\mathscr{L}$, as those who are approached by the charity. Let $l$ be the number of people in the set $\mathscr{L}$. Then define $\mathscr{F}$ to be the set of followers, where $\mathscr{F}$ is the complement of $\mathscr{L}$. Since the people who are chosen to be leaders must agree to do it, they must all be at least as well off being a leader as not. Of course, there are many ways a charity can make a leader better off than nonleaders. It can, for instance, offer a quid pro quo such as choice seats in return for a major gift to the opera. Or it can provide a warm glow or prestige in the form of an award or mention in the symphony program. At this point I shall not consider any of these effects, although I shall return to this possibility later. Instead, assume that the charity can affect utility only through consumption of $x$ and $G$.

Selecting the leaders amounts to letting this group collude to be first movers. What is the advantage in this? Varian (1994) analyzed a very simple model of sequential provision of public goods and found that the first mover is always better off. The reason is that a

\footnotetext{
${ }^{12}$ It is not uncommon for fund-raisers who gather large pledges to have a legal contract drawn up between the donor and the organization. The reason for this is that fund-raisers make many plans contingent on the anticipation of the promised cash; hence they cannot risk a change of heart. As we shall see, the leaders would actually prefer to have their pledge binding as well.
} 
first mover can commit to more free riding than a second mover. Through a similar means, the charity can give its first movers just such an advantage.

Before I provide a more general model, let us look at some examples to illustrate the issues. For ease of exposition, assume that everyone has identical preferences and identical wealth and, hence, everyone has identical $\tau$. In each of the three examples to follow, the fund drives will be allowed to have a leadership stage in which a game among the leaders results in binding commitments. These pledges are then announced to the community, at which time a Nash equilibrium contribution game is played among the rest of society. For these examples the cost of fund-raising will be ignored.

Example 1: $\sum_{i \in \mathscr{L}} g_{i}^{*}=\tau$. In this case the charity would ask all the members of the group of leaders to pledge $g_{i}^{*}$. Looking ahead, the leaders know that if they all do this, then the result will be an equilibrium with total contributions of $G^{*}$. Since this is better than the Nash equilibrium of $G=0$ and since none of the leaders would rather be followers, all members of the leaders will pledge to give $g_{i}^{*}$. Note that there is also an equilibrium at $g_{i}=0$ for all the leaders in the leadership stage. However, if the fund-raiser collects pledges of the form "I will pledge $y_{1}$ only if all other leaders pledge $\left(y_{2}, \ldots\right.$, $y_{l}$ ), ' then, as discussed later, a subgame perfect equilibrium in the leadership stage will have every leader pledging $g_{i}^{*}$, conditional on the pledge of $g_{j}^{*}$ from other leaders (Admati and Perry 1991).

Example 2: $\sum_{i \in \mathscr{L}} g_{i}^{*}<\tau$. In this case there is no way for the charity to specify any contributions by the leaders that would both meet the threshold of $\tau$ and make each of the leaders better off than if they had been followers. Hence, the group of leaders is too small.

Example 3: $\sum_{i \in \mathscr{L}} g_{i}^{*}>\tau$. Here the leaders will each be better off committing to some $g_{i}$ such that $g_{i}^{*} \geq g_{i}$ and $\sum_{i \in \mathscr{L}} g_{i} \geq \tau$. Since those members of $\mathscr{F}_{F}$, the followers, each have donation functions $g_{i}=f_{i}\left(m_{i}\right.$ $\left.+G_{-i}\right)-G_{-i}$ and $-1<f_{i}^{\prime}-1<0$, if the members of $\mathscr{L}$ give a little less than $g_{i}^{*}$, then the members of $\mathscr{F}$ will each give a little more. Hence, $G$ will not fall in equilibrium by the amount by which the leaders reduce their contributions. Since we know from the definition of $g_{i}^{*}$ that each individual's marginal rate of substitution equals one when everyone gives $g_{i}^{*}$, the members of $\mathscr{L}$ can be made better off by committing to giving an amount below $g_{i}^{*}$. As long as their gifts are large enough to surpass $\tau$, they will all be better off for agreeing to be leaders, and the public good will be provided at an interior point.

Notice that the outcome of example 3 is that, while the public good is provided, it is somewhat below $G^{*}$. This result matches the predictions in Varian (1994). Hence, while the provision of public 
goods will be greater than zero in equilibrium with fund-raisers, it may also be less than $G^{*}$. Next this model will be solved in more detail.

\section{B. The Game among the Leaders}

Generalize the examples above in two ways. First, imagine that individuals are heterogeneous; hence each $g_{i}^{*}$ and $\tau_{i}$ is unique. Second, assume that the charity faces costs of fund-raising that increase with the size of the leadership group ${ }^{13}$ so $c=c(l)$ and $c^{\prime}>0$. Furthermore, assume that the cost of organizing everyone, $c(n)$, is prohibitively high.

Assume that the costs of fund-raising must be paid with the funds collected. So if $l$ is the number of leaders and total contributions are $G$, then consumption of charity by everyone will be $G-c(l)$. Also assume that the objective of the charity is to provide the greatest level of these net contributions, $G-c(l)$, as possible. This now changes the calculus of the problem slightly. For a given cost, the equilibrium in the convex case will now be below $G^{*}$. This adds one more reason for the charity to want to minimize on costs. For complete generality we should now think of $G^{*}$ as a function of the costs, that is, $G^{*}=G^{*}(c)$ and $G^{*^{\prime}}<0$. Likewise, we should also think of $\tau$ as depending on costs: $\tau_{i}=\tau_{i}(c)$ and $\tau_{i}^{\prime}>0$.

In constructing the game among the leaders, we need to keep in mind the subgame played by the followers. They will take the pledges of the leaders as given and play a simultaneous contributions game. For instance, for a given $c(l)$, if the leaders by coincidence were each to give $g_{i}^{*}(c(l))$ and if $\sum_{i \in \mathscr{L}} g_{i}^{*}-c(l) \geq \tau_{k}$, for some $k$ in $\mathscr{F}$, then the followers would each give $g_{i}^{*}(c(l))$ as well. This follows from the definition of Nash equilibrium. However, if the leaders were each to give an amount below $g_{i}^{*}(c(l))$, but with a total still above the $\tau$ necessary to get an interior equilibrium, then, as shown earlier, the followers would respond with gifts greater than $g_{i}^{*}(c(l))$ and hence make up some of the difference. As long as $\sum_{i \in \mathscr{L}} g_{i}^{*}-c>\tau_{k}$, there will be room for the leaders to make smaller gifts and increase their own utility.

The objective of the fund-raiser will be to find the set of leaders, set a goal for leadership contributions, and choose a game among the leaders that will guarantee that the goal is met. The ultimate

\footnotetext{
${ }^{13}$ For instance, the more people there are to organize as leaders, the higher the cost in terms of meetings, negotiations, and legal advice; whereas certain economies of scale, such as billboards, advertisements, and mailings, will prevent much cost savings among the followers as $l$ grows.
} 
objective is to reach the highest net contributions. Once again, let us build up the logic of the model by starting with a special case. Suppose that the charity has identified the optimal set $\mathscr{L}$ and that $\sum_{i \in \mathscr{L}} g_{i}^{*}(c(l))-c(l)=\tau_{\min }(c(l))$, where $\tau_{\min }$ is the lowest $\tau$ among the set of followers. Now the charity needs to implement a game among the leaders that will have each member giving $g_{i}^{*}$.

There are at least two games that the charity could choose from. First, notice that this problem is identical to a game in which a group of individuals $\mathscr{L}$ must provide a discrete public good at the level $\tau_{k}+c(l)$. A mechanism suggested by Bagnoli and Lipman (1989) shows that in a simultaneous play game, $g_{i}=g_{i}^{*}$ is an equilibrium. However, $g_{i}=0$ is also an equilibrium. An alternative is presented by Admati and Perry (1991). They derive a model with two agents who alternate making gifts. On an agent's turn he can increase, but not decrease, his contribution. Admati and Perry show that under reasonable assumptions this game will have an equilibrium at the desired level, although it also cannot be guaranteed. However, if agents are allowed to make contributions with conditional statements of the form "I will give $X$ if the other person gives $Y$,' then the desired equilibrium will always be met. Moreover, the equilibrium is identical to that of an alternating offers bargaining problem. ${ }^{14}$

There are many other mechanisms that the charity could use in this case to get the members of $\mathscr{L}$ to give $g_{i}^{*}(c(l))$. Which mechanism the charities use is beside the point of this analysis. Hence, the mechanism used among the leaders will be treated as a black box.

How do things change when the optimal $\mathscr{L}$ is such that $\sum_{i \in \mathscr{L}}$ $g_{i}^{*}(c(l))-c(l)>\tau_{\min }(c(l))$ ? The leaders can look ahead to the contribution stage and know that their contributions will determine the ultimate equilibrium. They could collude to set their contributions at the level that will maximize their own utility, taking the followers as Nash responders to their leadership gift. Now define $\tau *+c(l)$ as the collusive level of giving by the leadership givers that maximizes their collective welfare as first movers. That is, if the leadership givers commit to giving an aggregate level $\tau *$, with an implied allocation of gifts so that $\sum_{i \in \mathscr{L}} g_{i}-c(l)=\tau *$, then when the followers move to the contribution stage, the result will maximize the utility of the leaders. Hence, in the leadership phase, the charity should set the goal of

\footnotetext{
${ }^{14}$ A related mechanism designed by Cornelli (1996) deals with providing a private good with large fixed costs in which individuals have unitary demands, such as a concert series. Cornelli finds individuals paying different amounts in equilibrium. She considers a generalization of her model to privately provided public goods. Unfortunately, she shows that her mechanism is impractical for large populations. If we think of $\tau_{\min }$ as a public good among leaders, however, Cornelli's mechanism could also be considered as another means to raise the critical threshold.
} 
the leaders at $\tau^{L}=\max \left\{\tau^{*}, \tau_{\min }\right\}$. With the goal for the leaders at $\tau^{L}$, the charity then runs a game among these leaders to meet this goal.

Finally, how does the charity choose the members of $\mathscr{L}$ ? The charity now faces a difficult nonlinear problem. One complication is the tension between $\tau$ and $g^{*}$. To keep the contributions of the leaders as high as possible, the charity should choose those with the highest $g^{*}$ 's. But they should leave out people with low $\tau$ 's since they need to surpass the $\tau$ of only one individual in $\mathscr{F}$. But people with high $g^{*}$ 's are also likely to have low $\tau$ 's, and they are likely to be the wealthy. Hence, depending on the distribution of preferences and incomes, the charity can adopt any number of strategies. Unless we make stricter assumptions about preferences and income distributions, it is impossible to present a solution to the charity's problem..$^{15}$

The model now generally characterizes the behavior of charities and fund-raisers in the economy. Fund-raisers organize their most generous givers and coordinate their contributions before announcing a general fund drive. The fund-raiser's rule of thumb-variously stated as raising one-third of the goal or as getting commitments from the 20 top contributors before announcing the general fund drive-is also captured by this model. The only assumptions made here to distinguish the model from prior models of privately provided public goods are, first, that there is a range of increasing returns in the production of the public good and, second, that fundraising is costly.

\section{A Note about Commitment}

A key assumption in the model just described is that the first movers are able to commit to their actions. There has been an active discussion in the game theory literature on commitment in sequential games. Bagwell (1995), for instance, shows that in a two-person game, if the second mover has any degree of uncertainty (over an infinite support) about the first mover's choice, then the simultaneous play Nash equilibrium will result, even though the game is played sequentially. Intuitively, this holds because the second mover must be willing to choose the sequential-game equilibrium move regardless of the information he gets about the choice of the first mover. This in turn gives the first mover an incentive to cheat on the sequen-

\footnotetext{
${ }^{15}$ It is, however, possible to characterize that solution. Consider some arbitrary partition of individuals into leaders and followers. Define $\tau_{\min }=\min \left\{\tau_{i}: j \in \mathscr{F}\right\}$ as the lowest $\tau$ among the followers. Then if $\sum_{i \in \mathscr{L}} g_{i}^{*}(c(l))-c(l) \geq \tau_{\min }(c(l))$, where $l$ is the number of members of $\mathscr{L}$, this partition is "viable"; i.e., it is capable of overcoming the zero equilibrium. The charity must then search among all the viable partitions such that it chooses the partition that will result in the highest $G-c(l)$.
} 
tial-game equilibrium outcome. As a result, the second mover will assume, regardless of information, that the first mover has indeed cheated. Hence, subgame perfection leads to the simultaneous play equilibrium. Bagwell's results are naturally extended to games with many first and second movers. The only way for first movers to maintain an advantage is to make their moves perfectly observable.

In the models presented above, the first mover is either the government or the leadership givers. The government can make its contribution observable by issuing the cash ex ante. Indeed, this is often how the government works. Even in so-called challenge grants the government will typically give money contingent only on a plan to raise privately three or four times the challenge grant funds. ${ }^{16}$

For leaders to commit is a bit more complicated. The fact that general fund drives are often initiated with large press conferences and major donors make legally enforceable pledges can be seen as an effort to make the leadership gifts credible and known. However, it is difficult to credibly prevent first movers from giving again. While leadership givers may not be able to commit to not giving more than the leadership gift, they can clearly commit to giving no less. ${ }^{17}$ If we allow that leaders, in the contribution stage, can increase their gifts as part of the simultaneous provision game, then the results in this paper remain the same. The only difference would be that leaders will have no particular first-mover advantage, except the possible social effects discussed below. If, on the other hand, leaders and followers are allowed to alternate moves ad infinitum, then the game becomes far more complex. ${ }^{18}$ There may be a benefit to future research that explores these alternatives.

\section{Warm Glow, Prestige, and Social Effects}

Several authors have argued that a model of warm-glow giving, in which individuals behave as though there is some private goods benefit from the act of giving, captures the data much better than the "pure altruism" model just described. ${ }^{19}$ The warm glow may enter

\footnotetext{
${ }^{16}$ See Challenge (1996) regarding challenge grants. The only penalty for failure to meet goals for private fund-raising is a lower likelihood of future federal grants.

${ }^{17}$ Large gifts are often secured with contracts and legally binding letters of intent. Failure to meet these obligations has resulted in lawsuits.

${ }^{18}$ Work by Bilodeau and Slivinski (1996a) indicates that such a situation may give leaders an incentive to actually increase their gift in the first stage. Also, games with alternating moves in two-person provision point models, such as Admati and Perry (1991), show a first-mover advantage, although the mechanism is not generally $\mathrm{Pa}$ reto efficient.

${ }^{19}$ See Cornes and Sandler (1984), Steinberg (1987), and Andreoni (1989, 1990). This view has been supported by various experimental and econometric studies (see, e.g., Kingma 1989; Andreoni 1995).
} 
the model through any number of mechanisms, but the important component is that utility depends, at a minimum, on one's own contribution, so $u_{i}=u_{i}\left(x_{i}, G, g_{i}\right)$.

How would warm-glow giving affect the results just stated? The answer is that the basic result would remain unchanged: if the government or fund-raisers can reach some critical mass of provision, they can eliminate the zero equilibrium. The difference is that such efforts can have an even bigger bang for the buck with a warm glow. The reason is that, as shown in Andreoni (1989), lump-sum taxes on warm-glow givers will generally be incompletely crowded out. Hence, if the government raises an amount of tax $T$ to get the economy off the zero equilibrium, the resultant equilibrium will be above the $G^{*}$ defined as the unique interior equilibrium in the convex case. ${ }^{20}$

Related work by Harbaugh (1998) introduces the concept of prestige as the benefit individuals might get from having the size of their gifts known to others. A distinguishing feature of leadership gifts is that the givers are often named publicly and, as Harbaugh notes, the sizes of their gifts are often revealed. Prestige may matter because, for instance, there are benefits to business owners in advertising their companies or to lawyers or accountants in signaling their honesty and integrity; or, as Glazer and Konrad (1996) hypothesize, people may simply get consumption value from sending signals of their wealth. All of these are various ways of saying that if there is a warm glow, then there may be an additional glow to the members of $\mathscr{L}$; hence they may be willing to pay more to the public good as leaders than as followers. As a result, an even smaller group of leaders may be needed in order to reach the threshold. ${ }^{21}$ Moreover, the amount collected from these people may easily exceed the convex case; hence, total contributions could be larger as well. Thus warm glow and prestige can generate an even bigger impact for fundraising than in the case of perfect altruism and pure public goods.

A third possible effect is "social comparison." Sociologists and

${ }^{20}$ Technically, all that we need to get results similar to those discussed above is to assume that all goods are normal. Preferences with a warm glow, $u_{i}\left(x_{i}, G, g_{i}\right)$, generate a demand function $g_{i}=f_{i}\left(m_{i}+G_{-i}, G_{-i}\right)-G_{-i}$. As long as $-1<$ $d g_{i} / d G_{-i}=\left[\partial f / \partial\left(m_{i}+G_{-i}\right)\right]+\left(\partial f / \partial G_{-i}\right)-1<0$, the principal results hold, with those that rely on complete crowding out excluded. The propositions using complete crowding out are even stronger than those using incomplete crowding. Hence, the general result regarding government taxation (under the assumption that there is no warm glow from paying taxes) has the flavor of corollary 3. It is interesting to note that this holds whether one assumes that the warm glow is felt only when $G \geq \bar{G}$ or for all levels of $G$.

${ }^{21}$ In fact, if the value of being a leader is large enough, then adding leaders may have other benefits above simply meeting a threshold. Such strategies are, unfortunately, beyond the scope of this paper. 
other social scientists stress how one person's gift may act as a model for another's. People who want to do their "fair share" may look to others around them to get an idea of what gift is appropriate. One might imagine that leadership gifts serve to set some standard for fair share. Let $G^{\mathscr{L}}$ be the contributions of the leadership group, and let $d_{i}=d\left(g_{i}, G^{\mathscr{L}}\right)$ be some distance function between one's own gift and a standard set by the leadership gifts. Then utility could look something like $u_{i}=u_{i}\left(x_{i}, G, 1 / d_{i}\right)$. Analysis of this model would proceed just as in the warm-glow case, except now $G^{*}$ and $\tau_{i}$ will also depend on the $G^{\mathscr{L}}$ determined in the leadership stage, with $G^{*}$ increasing and $\tau_{i}$ decreasing in the leadership gifts.

One final word about social effects is that they may be creating a nonconvexity in themselves. If certain charities become fads or if people want to get involved only if enough others show interest, then there may be a cascading effect of participation in charity. If this is so, then it shows one more role for seed money, that is, to create social momentum behind a cause.

\section{Subsidizing Gifts}

In addition to direct grants, another instrument available to both government and leaders is subsidies or, as they are sometimes called, matching grants. Subsidies are, of course, already a part of government policy. By giving to tax-exempt organizations, givers who itemize their taxes gain a subsidy. Much less common, however, are matching grants by the government to specific charities.

In private fund-raising campaigns, matching gifts are occasionally observed. Some corporations offer to match their employees' contributions. A common tool in fund-raising for public broadcasting is the "challenge grant," where an individual promises to give, for instance, $\$ 1,000$ if a certain number or amount of pledges is received by a specified deadline. Still, general offers of matching grants, where the more an individual gives the more another will give in return, remain relatively rare.

In this section I discuss generalizations of the model above to include the possibility for subsidies in addition to direct grants. I shall look at both government subsidies and leadership subsidies. The result is that indeed subsidies should be rare.

\section{A. Government Subsidies}

There are several ways in which the government could offer a subsidy. It could, for instance, earmark a certain group of philanthropists and offer a subsidy to just those people. In a way this is like 
making the government part of the group of leaders described in the last section. Rather, what I have in mind here is a general offer by the government to give $s$ dollars to the charity for every dollar the charity raises privately, with the subsidy paid from general tax revenues. This subsidy could be combined with direct grants or used alone. It is important to note that the question being asked here is not whether there is an optimal subsidy. This has been addressed elsewhere. Instead, the question is whether the government could get a bigger bang for the buck by using some of its money on subsidies rather than on direct grants. ${ }^{22}$

First, could government remove the zero equilibrium with a subsidy alone? The answer here is clearly no. From the logic of Section V, to guarantee that $\bar{G}$ will be met, the government must offer a subsidy of at least $\bar{s}$, where $\bar{s}$ solves

$$
u_{i}\left(m_{i}-(1-\bar{s}) \bar{G}, \bar{G}\right) \equiv u_{i}\left(m_{i}, 0\right)
$$

for at least one $i$. Since $\bar{G}$ may be many times $m_{i}$ for most $i$, the subsidy may need to be quite high. But to get one person to prefer to give, the government will have to subsidize all individuals by $\bar{s}$. This is an unlikely scenario.

Next turn the question to one of incremental changes. Imagine that the government has chosen lump-sum taxes $t_{i}$ as described in Section V so that they just reach the minimum $\tau$ necessary to get an interior equilibrium. Now let us ask whether they can shave some revenue from the $t_{i}$ 's to devote the money to subsidies and increase welfare.

An individual's budget constraint is now $x_{i}+(1-s) g_{i}=m_{i}-t_{i}$. Next, determine the taxes on others, $\tau_{i}$, necessary to make an individual willing to provide $\bar{G}$ for this given $s$. To provide $\bar{G}$ he must make a gift of $g_{i}=\bar{G}-\tau_{i}-t_{i}$. Substituting this into the budget constraint, we see that $\tau_{i}=\tau_{i}(s)$ is defined implicitly as the solution to

$$
u_{i}\left(m_{i}-s t_{i}-(1-s)\left(\bar{G}-\tau_{i}\right), \bar{G}\right) \equiv u_{i}\left(m_{i}, 0\right) .
$$

This subsidy will imply a new Nash equilibrium, $G^{N}(s)$. Hence, the new subsidy will cost the government revenue in the amount $R(s)=$ $s G^{N}(s)$.

Does $\tau(s)$ fall fast enough to free up tax revenues to pay for the subsidy $R(s)$ ? It is easy to verify that $d \tau(s) / d s=(T-\bar{G}) /(1-s)$

22 There has been discussion in the literature about whether subsidies can crowd out other giving. Andreoni and Bergstrom (1996) show that, while complete crowding out is possible, it is also possible to choose subsidy schemes that are effective. The details of any subsidy scheme are not essential for this discussion, although it is clearly assumed that an effective subsidy would be chosen. 
and $d R(s) / d s=G^{N}(s)+\left[s d G^{N}(s) / d s\right]$. Evaluating both of these at $s=0$, we see that

$$
\begin{aligned}
& \left.\frac{d \tau(s)}{d s}\right|_{s=0}=-(\bar{G}-T), \\
& \left.\frac{d R(s)}{d s}\right|_{s=0}=G^{N} .
\end{aligned}
$$

However, by definition, $G^{N} \geq \bar{G}$, so clearly $G^{N}>\bar{G}-T$. This means that there is no room for the government to convert tax dollars from seed grants to subsidies. ${ }^{23}$ If the total budget that the government can devote to the charity is $T$, it is best to spend it all as a direct grant. Only when the government's budget is large should it consider adding subsidies.

The result is that indeed government matching grants to specific charities are likely to be rare and will not replace seed grants. One should emphasize again that this is not a normative exercise, but a positive one. If a government is constrained and cannot afford Pigouvian subsidies to all deserving public goods, it may be best to provide seed grants to several charities to nudge them into existence. This indeed appears to capture the behavior of the government.

\section{B. Leadership Subsidies}

Now consider whether leadership givers would ever choose to subsidize the followers by offering a matching grant. Note first that we must look only at subsidies that operate at the margin. For instance, an offer to match dollar for dollar the first million dollars of gifts to a $\$ 10$ million fund drive is inframarginal and hence should operate as an ordinary direct grant. To be true subsidies, they must match the last dollars given.

As in the case with government subsidies, it is unlikely that subsidies alone will be sufficient for the leaders to eliminate the zero equilibrium. So again, we can start at a solution found in Section V to see whether it can be adjusted to include a subsidy from the leaders to the followers.

Begin by redefining $\tau_{i}(s)$ among the followers as the solution to

$$
u_{i}\left(m_{i}-(1-s)\left(\bar{G}-\tau_{i}\right), \bar{G}\right) \equiv u_{i}\left(m_{i}, 0\right) .
$$

${ }^{23}$ This does not rule out more complicated subsidy schemes, such as subsidizing only gifts above a certain minimum. Such a step subsidy is implicit in the test for itemized deductions. However, designing such a step subsidy for specific charities would be unwieldy and, again, is virtually never done. 
Assume for simplicity that the leaders provide the optimal $\tau$ given an announced $s$. Then the cost of the subsidy to the leaders will be $R(s)=s\left[G^{N}(s)-\tau(s)\right]$. Analogously to (3), differentiating $\tau(s)$ and $R(s)$ and evaluating at $s=0$, we find

$$
\begin{aligned}
& \left.\frac{d \tau(s)}{d s}\right|_{s=0}=-(\bar{G}-\tau), \\
& \left.\frac{d R(s)}{d s}\right|_{s=0}=G^{N}-\tau .
\end{aligned}
$$

Hence, the net cost to the leaders of introducing a subsidy is simply $G^{N}-\bar{G}$. Again by definition, $G^{N} \geq \bar{G}$, so adding a subsidy will cost the leaders more money. ${ }^{24}$ This clearly stacks the deck against a leadership-sponsored subsidy. However, the shape of the $G^{N}(s)$ function may restore some chance. As $s$ increases, presumably $G^{N}$ will rise as well. There may be some $s>0$ such that the leaders are willing to pay the extra cost in order to get the extra public goods. I cannot tell for sure whether this will happen, however, without more assumptions on preferences and distributions of income. Hence, except for extremely small $s$, one cannot rule out subsidies by leaders, although one can say that subsidies, if they are used at all, will complement and not replace ordinary seed gifts. Again, this is in line with the observed facts.

\section{Conclusion}

This paper shows that models of privately provided public goods can include a role for fund-raising. Moreover, the results of the model accord quite nicely with the actual role that fund-raising and seed money seem to play. Also, many of the troubling features of prior models of charitable giving, such as complete crowding out and neutrality of income redistribution, no longer hold under some circumstances in this model, and the addition of warm-glow givers has a natural application. Hence, further work that looks more carefully at the role of fund-raising may ultimately help us to gain better understanding of charitable institutions, private initiatives, and government policies to encourage them.

The model presented here relied entirely on the fact of a noncon-

\footnotetext{
${ }^{24}$ Notice that this mathematics implicitly assumes that leaders subsidize their own direct gifts as well as those of the followers. There is no loss of generality in doing so if the gifts of the leaders are redefined to account for this "double giving" of subsidizing themselves.
} 
vexity in the production of the public good for the result. While it was assumed that the nonconvexity came from the technology of producing the public good, it might also be possible for the nonconvexity to be the result of preferences as well. For instance, suppose that individuals want to give to a fund-raising campaign but would value their gift more if the campaign were "successful," that is, met its goals. Hence, the marginal rate of substitution could be increasing with donations over a range until it becomes clear that indeed the campaign goals will be met. In the extreme case, the marginal utility could be zero until the goal, $\bar{G}$, is reached and positive thereafter. Thus this nonconvexity in preferences could be represented in a model formally identical to the model in which the nonconvexity comes from technology. In this sense, continuing campaigns that are able to create "bandwagon effects" of this kind could also exhibit qualities of leadership givers even in the absence of any increasing returns in the production of the public good.

In addition to exploring nonconvexities in preferences, there are many other fruitful ways for research on fund-raising to continue. One important avenue is to study continuing campaigns. Harbaugh (1998) has noticed that law schools and operas, for instance, often announce contributions of donors and that the donations are reported in "bracket" amounts rather than the actual amounts. He finds that, under certain assumptions on preferences, such a strategy is optimal for fund-raisers. Other attempts to capture the stylized facts of fund-raising in a theoretical model of continuing campaigns would be useful. Ultimately, the models can address important policy questions, such as how fund-raisers' strategies change as levels of government grants and tax subsidies change.

Another possible area of research is to model more carefully the sequential nature of donations. Perhaps early donations or large donations convey some information about the quality of the charity. ${ }^{25}$ How a charity chooses the sequence of donor solicitations, or the order in which individuals volunteer to contribute, may be a critical factor in the fund-raising strategy.

Finally, it will also be important to devote more research, both theoretical and empirical, to understanding the motives and objectives of charitable entrepreneurs, and whether they are compatible with the views of donors. ${ }^{26}$ There are also more subtle issues, such as

\footnotetext{
${ }^{25}$ For instance, Vesterlund (1998) examines a model in which asymmetric information about the quality of a charity leads to gifts as signals of that quality.

${ }^{26}$ Some authors have begun to ask these questions. Bilodeau and Slivinski (1996a), for instance, ask whether it is "rational" to impose a nondistribution constraint voluntarily, i.e., to choose to charter the firm as nonprofit rather than for profit. Bilodeau and Slivinski (1996b) look at selection of heterogeneous agents into becoming charity managers. Finally, Bilodeau and Slivinski (1997) study charities that
} 
whether a charitable organization is incentive compatible, whether charities are able to act as private implementation mechanisms, why some charity markets are "contested" by competing charities versus "collusive" with a single charity, and whether united fund drives are better than competing fund drives. Addressing these issues fully will require a fundamental understanding of charities and their interactions with donors. Understanding this interaction will help form better policy regarding the charitable sector of the economy.

\section{References}

Admati, Anat R., and Perry, Motty. "Joint Projects without Commitment." Rev. Econ. Studies 58 (April 1991): 259-76.

Andreoni, James. "Privately Provided Public Goods in a Large Economy: The Limits of Altruism." J. Public Econ. 35 (February 1988): 57-73.

_. "Giving with Impure Altruism: Applications to Charity and Ricardian Equivalence." J.P.E. 97 (December 1989): 1447-58.

- "Impure Altruism and Donations to Public Goods: A Theory of Warm-Glow Giving." Econ. J. 100 (June 1990): 464-77.

_. " "An Experimental Test of the Public-Goods Crowding-Out Hypothesis." A.E.R. 83 (December 1993): 1317-27.

—_. "Cooperation in Public Goods Experiments: Kindness or Confusion?" A.E.R. 85 (September 1995): 891-904.

Andreoni, James, and Bergstrom, Theodore C. "Do Government Subsidies Increase the Private Supply of Public Goods?" Public Choice 88 (September 1996): 295-308.

Andreoni, James, and McGuire, Martin C. "Identifying the Free Riders: A Simple Algorithm for Determining Who Will Contribute to a Public Good." J. Public Econ. 51 (July 1993): 447-54.

Auten, Gerald E.; Cilke, James M.; and Randolph, William C. “"The Effects of Tax Reform on Charitable Contributions." Nat. Tax J. 45 (September 1992): 267-90.

Bagnoli, Mark, and Lipman, Barton L. "Provision of Public Goods: Fully Implementing the Core through Private Contributions." Rev. Econ. Studies 56 (October 1989): 583-601.

Bagnoli, Mark, and McKee, Michael. "Voluntary Contribution Games: Efficient Private Provision of Public Goods." Econ. Inquiry 29 (April 1991): 351-66.

Bagwell, Kyle. "Commitment and Observability in Games." Games and Econ. Behavior 8 (February 1995): 271-80.

Bergstrom, Theodore C.; Blume, Lawrence E.; and Varian, Hal R. "On the Private Provision of Public Goods.' J. Public Econ. 29 (February 1986): 25-49.

Bilodeau, Marc, and Slivinski, Al. "Rational Nonprofit Entrepreneurship." Manuscript. Indianapolis: Indiana University-Purdue University; London: Univ. Western Ontario, 1996. (a) 
. "Volunteering Nonprofit Entrepreneurial Services." J. Econ. Behavior and Organization 31 (October 1996): 117-27. (b)

—_. "Rival Charities." J. Public Econ. 66 (December 1997): 449-67.

Challenge: Application Guidelines for Fiscal Year 1996. Washington: Nat. Endowment Arts, 1996.

Clotfelter, Charles T. "The Impact of Tax Reform on Charitable Giving: A 1989 Perspective." In Do Taxes Matter? The Impact of the Tax Reform Act of 1986, edited by Joel E. Slemrod. Cambridge, Mass.: MIT Press, 1990.

Cornelli, Francesca. "Optimal Selling Procedures with Fixed Costs." J. Econ. Theory 71 (October 1996): 1-30.

Cornes, Richard, and Sandler, Todd. "Easy Riders, Joint Production, and Public Goods." Econ. J. 94 (September 1984): 580-98.

Glazer, Amihai, and Konrad, Kai A. "A Signaling Explanation for Charity." A.E.R. 86 (September 1996): 1019-28.

Harbaugh, William T. "What Do Donations Buy? A Model of Philanthropy Based on Prestige and Warm Glow." J. Public Econ. 67 (February 1998): 269-84

Kelly, Kathleen S. "From Motivation to Mutual Understanding: Shifting the Domain of Donor Research." In Critical Issues in Fundraising, edited by Dwight Burlingame. New York: Wiley, 1997.

Khanna, Jyoti; Posnett, John; and Sandler, Todd. "Charity Donations in the UK: New Evidence Based on Panel Data." J. Public Econ. 56 (February 1995): 257-72.

Kingma, Bruce Robert. "An Accurate Measurement of the Crowd-Out Effect, Income Effect, and Price Effect for Charitable Contributions.' J.P.E. 97 (October 1989): 1197-1207.

Randolph, William C. "Dynamic Income, Progressive Taxes, and the Timing of Charitable Contributions." J.P.E. 103 (August 1995): 709-38.

Roberts, Russell D. "A Positive Model of Private Charity and Public Transfers." J.P.E. 92 (February 1984): 136-48.

—. "Financing Public Goods." J.P.E. 95 (April 1987): 420-37.

Rose-Ackerman, Susan. 'Charitable Giving and 'Excessive' Fundraising.' Q.J.E. 97 (May 1982): 193-212.

_. "Ideals versus Dollars: Donors, Charity Managers, and Government Grants." J.P.E. 95 (August 1987): 810-23.

Sandler, Todd. Collective Action: Theory and Applications. Ann Arbor: Univ. Michigan Press, 1992.

Steinberg, Richard S. "Voluntary Donations and Public Expenditures in a Federalist System." A.E.R. 77 (March 1987): 24-36.

Varian, Hal R. "Sequential Contributions to Public Goods." J. Public Econ. 53 (February 1994): 165-86.

Vesterlund, Lise. "The Information Value of Sequential Fundraising." Manuscript. Ames: Iowa State Univ., Dept. Econ., 1998.

Warr, Peter G. "Pareto Optimal Redistribution and Private Charity.' J. Public Econ. 19 (October 1982): 131-38.

- "The Private Provision of a Public Good Is Independent of the Distribution of Income." Econ. Letters 13, nos. 2-3 (1983): 207-11. 